\title{
Treatment of dye wastewater with permanganate oxidation and in situ formed manganese dioxides adsorption: Cation blue as model pollutant
}

\author{
Ruiping Liu ${ }^{a}$, Huijuan Liu ${ }^{a}, X_{\text {Zhao }}{ }^{a}$, Jiuhui Qu ${ }^{a}, *$, Ran Zhang ${ }^{\text {a,b }}$ \\ a State Key Laboratory of Environmental Aquatic Chemistry, Research Center for Eco-Environmental Sciences, Chinese Academy of Sciences, Beijing 100085, China \\ ${ }^{\mathrm{b}}$ College of Environmental Science and Engineering, Hebei University of Science and Technology, Hebei Province, 050018, China
}

\section{A R T I C L E I N F O}

\section{Article history:}

Received 29 June 2009

Received in revised form

24 November 2009

Accepted 24 November 2009

Available online 1 December 2009

\section{Keywords:}

Potassium permanganate

$\delta \mathrm{MnO}_{2}$

X-GRL

Adsorption

Oxidation

Dissolved Mn

\begin{abstract}
A B S T R A C T
This study investigated the process of potassium permanganate $\left(\mathrm{KMnO}_{4}\right)$ oxidation and in situ formed hydrous manganese dioxides $\left(\delta \mathrm{MnO}_{2}\right)$ (i.e., $\mathrm{KMnO}_{4}$ oxidation and $\delta \mathrm{MnO}_{2}$ adsorption) for the treatment of dye wastewater. The effectiveness of decolorization, removing dissolved organic carbon (DOC), and increasing biodegradable oxygen demand (BOD) were compared among these processes of $\mathrm{KMnO}_{4}$ oxidation, $\delta \mathrm{MnO}_{2}$ adsorption, and $\mathrm{KMnO}_{4}$ oxidation and $\delta \mathrm{MnO}_{2}$ adsorption. $\delta \mathrm{MnO}_{2}$ adsorption contributed to the maximum DOC removal of $65.0 \%$, but exhibited limited capabilities of decolorizing and increasing biodegradability. $\mathrm{KMnO}_{4}$ oxidation alone at $\mathrm{pH} 0.5$ showed satisfactory decrease of UV-vis absorption peaks, and the maximum $\mathrm{BOD}_{5} / \mathrm{DOC}$ value of 1.67 was achieved. Unfortunately, the $\mathrm{DOC}$ removal was as low as $27.4 \%$. Additionally, the great amount of acid for $\mathrm{pH}$ adjustment and the much too low $\mathrm{pH}$ levels limited its application in practice. $\mathrm{KMnO}_{4}$ oxidation and $\delta \mathrm{MnO}_{2}$ adsorption at $\mathrm{pH} 2.0$ was the best strategy prior to biological process, in balancing the objectives of decolorization, DOC removal, and BOD increase. The optimum ratio of $\mathrm{KMnO}_{4}$ dosage to X-GRL concentration $\left(R_{\mathrm{KMnO}} / \mathrm{X}\right.$-GRL $)$ was determined to be 2.5 , at which $\mathrm{KMnO}_{4}$ oxidation and $\delta \mathrm{MnO}_{2}$ adsorption contributed to the maximal DOC removal of 53.4\%. Additionally, the optimum pH for X-GRL treatment was observed to be near 3.0.
\end{abstract}

(C) 2009 Elsevier B.V. All rights reserved.

\section{Introduction}

Potassium permanganate $\left(\mathrm{KMnO}_{4}\right)$ is often used for $\mathrm{Fe}^{2+}$ and $\mathrm{Mn}^{2+}$ oxidation [1], arsenite oxidation [2], taste and odor control [3], disinfection by-products formation control [4], algae removal [5], and organic chemicals degradation (e.g., TCE and MTBE) [6] during water treatment and underground water rehabilitation. In strong acid conditions, $\mathrm{KMnO}_{4}$ exhibits high oxidative reactivity with oxidation potential $\left(E^{\mathrm{o}}\right)$ of $+1.51 \mathrm{~V}$, and its reductive product is $\mathrm{Mn}^{2+}$ (Eq. (1)). However, $\mathrm{KMnO}_{4}$ respectively shows $E^{\mathrm{O}}$ values of $+1.70 \mathrm{~V}$ and $+0.59 \mathrm{~V}$ in acidic-neutral $\mathrm{pH}$ and alkaline conditions, and results in the formation of hydrous manganese dioxide $\left(\delta \mathrm{MnO}_{2}\right)$ (Eqs. (2) and (3)).

In strong acid condition:

$\mathrm{MnO}_{4}^{-}+8 \mathrm{H}^{+}+5 \mathrm{e}^{-} \rightarrow \mathrm{Mn}^{2+}+4 \mathrm{H}_{2} \mathrm{O}+1.51 \mathrm{~V}$

\footnotetext{
* Corresponding author at: State Key Laboratory of Environmental Aquatic Chemistry, Research Center for Eco-Environmental Sciences, Chinese Academy of Sciences, P.O. Box 2871, Beijing 100085, China. Tel.: +86 1062849151 ; fax: +861062923558.

E-mail address: jhqu@rcees.ac.cn (J. Qu).
}

In alkaline condition:

$$
\mathrm{MnO}_{4}{ }^{-}+2 \mathrm{H}_{2} \mathrm{O}+3 \mathrm{e}^{-} \rightarrow \mathrm{MnO}_{2}(\mathrm{~s})+4 \mathrm{OH}^{-}+0.59 \mathrm{~V}
$$

In acidic-neutral $\mathrm{pH}$ :

$\mathrm{MnO}_{4}{ }^{-}+4 \mathrm{H}^{+}+3 \mathrm{e}^{-} \rightarrow \mathrm{MnO}_{2}(\mathrm{~s})+2 \mathrm{H}_{2} \quad \mathrm{O}+1.70 \mathrm{~V}$

The $\delta \mathrm{MnO}_{2}$ exhibited promising adsorptive activity due to its high surface area, and the active surface hydroxyl groups (i.e., $\equiv \mathrm{Mn}-\mathrm{OH}$ ). The adsorption of heavy metals, humic acid, and anions (e.g., arsenate, phosphate) has been investigated [7-10].

$\mathrm{KMnO}_{4}$ contributes to the degradation and transformation of organics species. Simultaneously, $\mathrm{KMnO}_{4}$ itself is reduced to $\delta \mathrm{MnO}_{2}$, which shows adsorptive reactivity towards the intermediates. However, rare studies focus on the effect of $\mathrm{KMnO}_{4}$ oxidation on the subsequent adsorption of oxidative intermediates onto in situ formed $\delta \mathrm{MnO}_{2}$.

Dye wastewater, which receives great concern due to its difficulty to treat, contains high intensity of color, high chemical oxygen demand (COD); and perhaps more serious, they are toxic and carcinogenic to aquatic living organisms [11,12]. Biological process is unlikely to achieve good performance if the biodegradability is not satisfactorily increased by chemical oxidation. Adsorption could not minimize the risk to environments, due to its inability in degrading dye molecules. The advanced oxidation processes (AOPs), such as $\mathrm{O}_{3}, \mathrm{H}_{2} \mathrm{O}_{2}$, Fenton's reagent, photo-Fenton reagent, 
Table 1

Molecular structure of the studied dye.

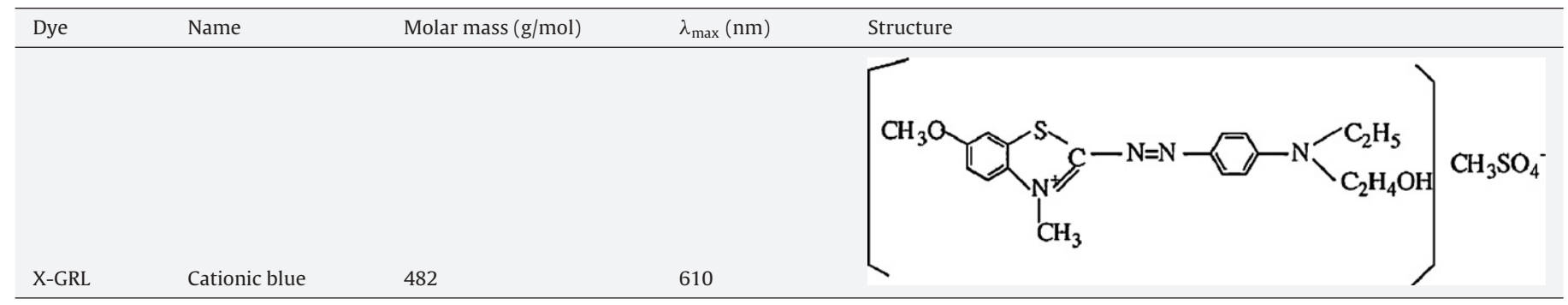

photo-catalysis reaction, and $\mathrm{UV}-\mathrm{H}_{2} \mathrm{O}_{2}$, contribute to satisfactory decolorization, degradation, and mineralization of dyes [13-16]. However, AOPs are rarely used in practice, owing to the complicate reactors and high costs. The development of effective, cheap, and easy-to-handle process is of crucial importance for the treatment of dye wastewater. $\mathrm{KMnO}_{4}$ has been proposed for the treatment of dye wastewater $[17,18]$. Xu et al. reported that $\mathrm{KMnO}_{4}$ at $\mathrm{pH} 0.5$ contributed to satisfactory decolorization of different dyes and the increase of $\mathrm{BOD}_{5} / \mathrm{COD}$ [17]. However, $\mathrm{KMnO}_{4}$ oxidation resulted in limited degradation of total organic carbon (TOC), and the $\mathrm{pH}$ level as low as 0.5 is often prohibited in engineering.

The study employed the azo dye of cationic blue (X-GRL) as model pollutant, and aimed: (1) to compare the variation of UV-vis spectrometry and DOC removal, and transformation of Mn species among processes of $\mathrm{KMnO}_{4}$ oxidation, $\delta \mathrm{MnO}_{2}$ adsorption, and $\mathrm{KMnO}_{4}$ oxidation with in situ formed $\delta \mathrm{MnO}_{2}$ adsorption (i.e., $\mathrm{KMnO}_{4}$ oxidation and $\delta \mathrm{MnO}_{2}$ adsorption); (2) to investigate the effect of oxidizing X-GRL by $\mathrm{KMnO}_{4}$ on the adsorption of intermediates onto in situ formed $\delta \mathrm{MnO}_{2}$; (3) to optimize the process of $\mathrm{KMnO}_{4}$ oxidation and $\delta \mathrm{MnO}_{2}$ adsorption for the treatment of dye wastewater.

\section{Materials and methods}

\subsection{Reagents}

The blue azo dye of cationic blue X-GRL (Shanghai Huacai Fine Chemicals Co. Ltd.) was directly used without pretreatment. Table 1 presents the main characteristics and structure of X-GRL. To prepare its stock solution, $\mathrm{X}-\mathrm{GRL}$ ash was first dissolved in deionized water, filtered through $0.45-\mu \mathrm{m}$ cellulose acetate filters, and then air-tightly kept in darkness at room temperature.

$\delta \mathrm{MnO}_{2}$ was prepared through reaction between $\mathrm{MnSO}_{4}$ and $\mathrm{KMnO}_{4}$ following the procedures reported by Murray [19]. X-ray diffraction (XD-3A) (Shimadzu Co., Japan) analysis showed low degree of crystallinity, indicating its similarity to what others referred to as $\delta \mathrm{MnO}_{2}$.

\subsection{Experimental procedures}

The initial X-GRL solution was prepared by the dilution of its stock solution in deionized water, and the concentration was controlled to be $200 \mathrm{mg} / \mathrm{L}$. No salts were additionally added to adjust the background ionic strength, and the $\mathrm{pH}$ of initial X-GRL solution was determined to be 4.5 . The adjustment of $\mathrm{pH}$ was not preceded except under the conditions that the background $\mathrm{pH}$ was additionally noted.

Batch experiments were conducted in capped flasks with continuous rotary shaking $(125 \mathrm{rpm})$ at $25 \pm 1^{\circ} \mathrm{C}$. $\mathrm{KMnO}_{4}$ was dosed into the X-GRL solutions in the processes of $\mathrm{KMnO}_{4}$ oxidation and $\mathrm{KMnO}_{4}$ oxidation and $\delta \mathrm{MnO}_{2}$ adsorption. In $\delta \mathrm{MnO}_{2}$ adsorption process, $\delta \mathrm{MnO}_{2}$ was freshly prepared before dosing.

\subsection{Analysis}

Samples were filtered through $0.45-\mu \mathrm{m}$ membrane filters to remove $\delta \mathrm{MnO}_{2}$ particles and the organic species that have adsorbed onto $\delta \mathrm{MnO}_{2}$ before analysis. The initial filtrate of each sample (about $5 \mathrm{~mL}$ ) was abandoned to avoid the side effect of filtration procedure on the experimental results. UV-vis spectra were recorded from 190 to $800 \mathrm{~nm}$ using a U-3010 UV-Vis spectrophotometer (Hitachi Co., Japan). Total organic carbon (TOC) was analyzed by UV-persulfate oxidation with a TOC Analyzer (Phoenix 8000) (Tekmar-Dohrmann Co.). The concentrations of Mn were determined using an atomic absorption spectrophotometer (Z6100) (Hitachi Co., Japan).

\section{Results and discussions}

3.1. Comparison of X-GRL removal between $\mathrm{KMnO}_{4}$ oxidation, $\delta \mathrm{MnO}_{2}$ adsorption, and $\mathrm{KMnO}_{4}$ oxidation and $\delta \mathrm{MnO}_{2}$ adsorption

\subsubsection{UV-vis spectrometry variation}

As being indicated from UV-vis analysis in Fig. 1a, X-GRL showed three absorption peaks at wavelengths of 202, 300, and $610 \mathrm{~nm}$, which were mainly attributed to benzene ring, azo linkage, and the multi-peaks of the functions within X-GRL. The ratio of absorbance at different wavelengths of 202,300, and $610 \mathrm{~nm}$ $\left(A_{202 \mathrm{~nm}} / A_{300 \mathrm{~nm}} / A_{610 \mathrm{~nm}}\right)$ was $1 / 0.24 / 2.04$ for X-GRL molecular.

The variation of UV-vis spectrometry between different processes such as $\mathrm{KMnO}_{4}$ oxidation, $\mathrm{KMnO}_{4}$ oxidation and $\delta \mathrm{MnO}_{2}$ adsorption, and $\delta \mathrm{MnO}_{2}$ adsorption was also compared in Fig. 1. Generally, the oxidation effect by $\mathrm{KMnO}_{4}$ contributed to more significant decolorization of X-GRL than the adsorption effect by $\delta \mathrm{MnO}_{2}$ did. The absorbance at $610 \mathrm{~nm}\left(A_{610 \mathrm{~nm}}\right)$, which was attributed to the azo linkage, significantly decreased to 0.01 within 4 min due to the oxidizing effect of $\mathrm{KMnO}_{4}$ at $\mathrm{pH} 0.5$ (Fig. 1b). The combined effects of $\mathrm{KMnO}_{4}$ oxidation and $\delta \mathrm{MnO}_{2}$ adsorption (Fig. 1c) at pH 2.0 also decreased $A_{610 \mathrm{~nm}}$ to low level of 0.03 after $3.67 \mathrm{~min}$. The azo linkage had been reported to be easily degraded in our former study [20]. Hu et al. [21] investigated the solid/liquid interface photodegradation mechanism of X-GRL adsorbed on the $\mathrm{TiO}_{2} / \mathrm{SiO}_{2}$ by FT-IR technique, indicating the disappearance of the characteristic $\mathrm{C}=\mathrm{N}$ stretching adsorption of penta-heterocyclic alky, bands of absorption from the benzene ring, and the $\mathrm{C}-\mathrm{N}$ of aromatic amide when the decolorization of X-GRL had achieved.

In comparison, $\mathrm{KMnO}_{4}$ at $\mathrm{pH} 0.5$ showed higher oxidative ability towards X-GRL than at $\mathrm{pH}$ 2.0. Quantitatively, after dosing $\mathrm{KMnO}_{4}$ for $97 \mathrm{~min}$, the ratios of $A_{202 \mathrm{~nm}} / A_{300 \mathrm{~nm}} / A_{610 \mathrm{~nm}}$, respectively changed to $1419 / 31 / 1$ at $\mathrm{pH} 0.5$ and to $928 / 21 / 1$ at $\mathrm{pH} 2.0$. The more significant variation of the ratios indicated the more complete degradation of X-GRL molecular. Actually, the oxidation of $\mathrm{X}$-GRL by $\mathrm{KMnO}_{4}$ at $\mathrm{pH} 0.5$ led to the appearance of new absorption peaks in the wavelength ranges from 330 to $400 \mathrm{~nm}$. These peaks decreased to some extent after $97 \mathrm{~min}$ of reaction, but the absorbance at $354 \mathrm{~nm}\left(A_{354 \mathrm{~nm}}\right)$ was still as high as 0.263 , indicat- 

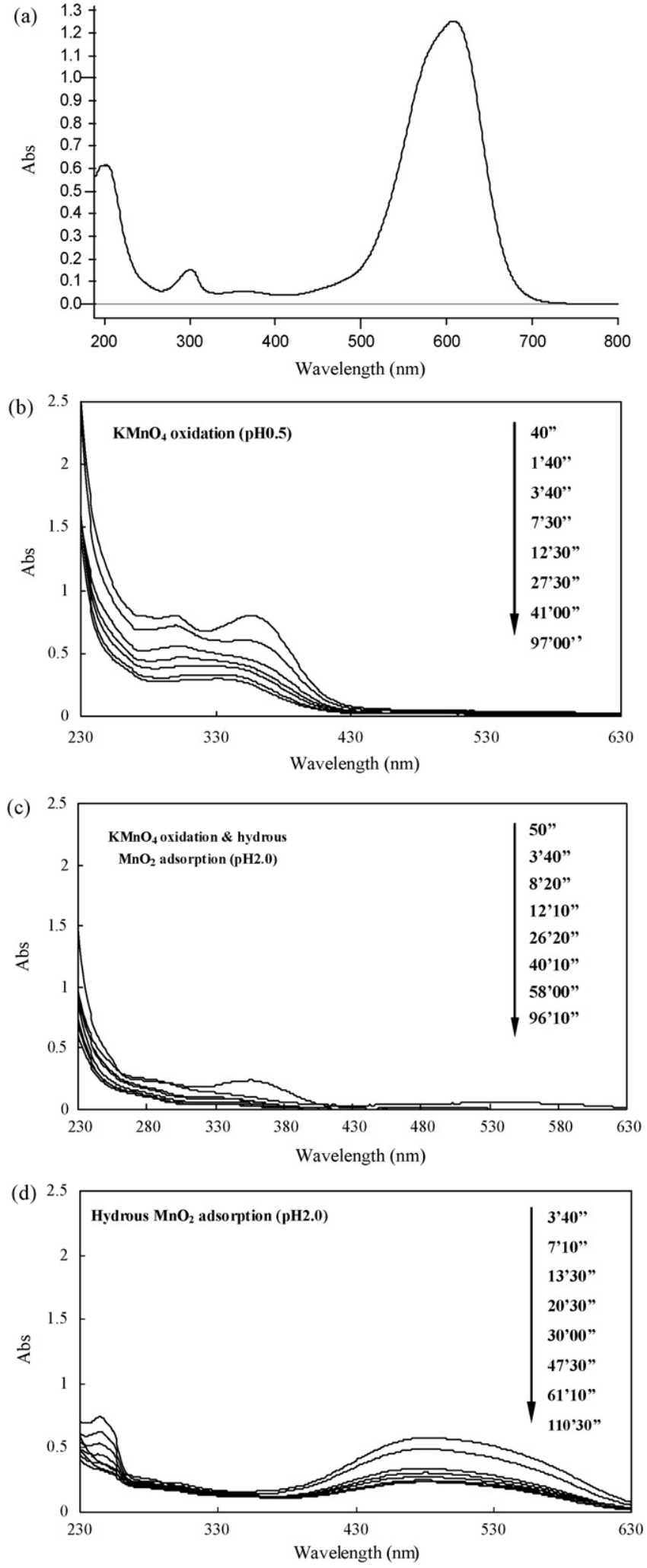

Fig. 1. Variations of UV-vis spectrometry for $\mathrm{KMnO}_{4}$ oxidation $(500 \mathrm{mg} / \mathrm{L}$ as $\left.\mathrm{KMnO}_{4}\right), \delta \mathrm{MnO}_{2}$ adsorption $\left(275 \mathrm{mg} / \mathrm{L}\right.$ as $\left.\mathrm{MnO}_{2}\right)$, and $\mathrm{KMnO}_{4}$ oxidation and $\delta \mathrm{MnO}_{2}$ adsorption $\left(500 \mathrm{mg} / \mathrm{L}\right.$ as $\left.\mathrm{KMnO}_{4}\right)$.

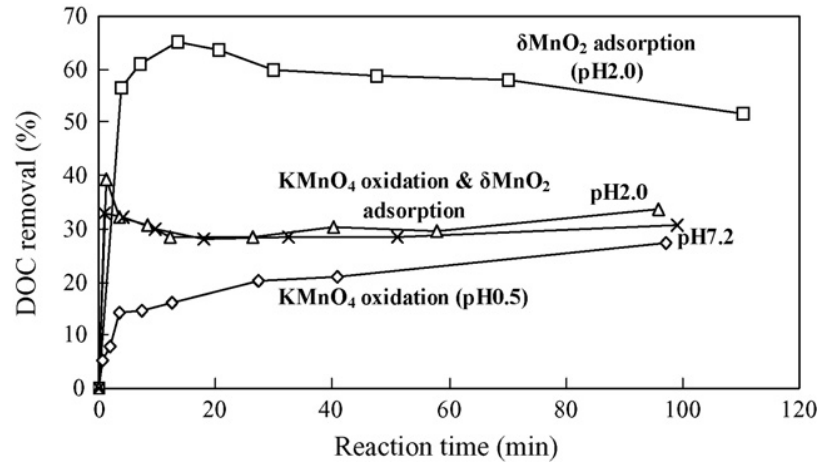

Fig. 2. DOC removal comparison among $\mathrm{KMnO}_{4}$ oxidation $\left(500 \mathrm{mg} / \mathrm{L}\right.$ as $\left.\mathrm{KMnO}_{4}\right)$ $\delta \mathrm{MnO}_{2}$ adsorption $\left(275 \mathrm{mg} / \mathrm{L}\right.$ as $\left.\mathrm{MnO}_{2}\right)$, and $\mathrm{KMnO}_{4}$ oxidation and $\delta \mathrm{MnO}_{2}$ adsorption $\left(500 \mathrm{mg} / \mathrm{L}\right.$ as $\left.\mathrm{KMnO}_{4}\right)$.

ing the formation of new functional groups due to $\mathrm{KMnO}_{4}$ oxidation at $\mathrm{pH}$ 0.5.

The adsorption effect of $\delta \mathrm{MnO}_{2}$ also contributed to remarkable removal of the X-GRL, as being indicated from the steady decrease of the absorbance at different wavelengths with longer reaction time (Fig. 1d). With reaction time increasing from 4 to $30 \mathrm{~min}, A_{610 \mathrm{~nm}}$ decreased from 0.063 to 0.022 . That adsorption of X-GRL onto $\delta \mathrm{MnO}_{2}$ dominated the removal of X-GRL and the decrease of UV-vis absorbance. However, it was noted that $\delta \mathrm{MnO}_{2}$ surfaces (i.e., $\equiv \mathrm{MnOH}$ ) also exhibited oxidative activity to X-GRL, as being indicated from the shift of absorption peaks. Quantitatively, the ratio of $A_{202 \mathrm{~nm}} / A_{300 \mathrm{~nm}} / A_{610 \mathrm{~nm}}$, respectively changed to $1 / 0.13 / 0.039$ and to $1 / 0.13 / 0.022$ at 30 and $110.5 \mathrm{~min}$, demonstrating the interfacial reactions between $\delta \mathrm{MnO}_{2}$ and X-GRL [20]. The electron transfer between Mn(IV) oxides and organics that adsorbed onto $\mathrm{Mn}(\mathrm{IV})$ oxides, mainly through interfacial oxidation/reduction reactions, had been reported before. Stone and Morgan studied the adsorption of 27 aromatic and nonaromatic compounds onto $\mathrm{Mn}$ (III, IV) oxide suspensions, and indicated the oxidative effect toward these organic species [22]. Comparatively, the oxidizing potential of $\delta \mathrm{MnO}_{2}$ was much weaker than that of $\mathrm{KMnO}_{4}$. The absorbance at $500 \mathrm{~nm}\left(A_{500 \mathrm{~nm}}\right)$ in the visible range was still as high as 0.23 at $110.5 \mathrm{~min}$, indicating the incomplete decolorization by $\delta \mathrm{MnO}_{2}$.

\subsubsection{DOC removal comparison}

Fig. 2 compares the DOC removal between $\mathrm{KMnO}_{4}$ oxidation, $\delta \mathrm{MnO}_{2}$ adsorption, and $\mathrm{KMnO}_{4}$ oxidation and $\delta \mathrm{MnO}_{2}$ adsorption. $\mathrm{KMnO}_{4}$ oxidation ( $\mathrm{pH} 0.5$ ) contributed to the steady increase of DOC removal with prolonged reaction time, which reached to maximum value of $27.4 \%$ after $97 \mathrm{~min}$. Xu et al. also reported the incomplete degradation of different dyes by $\mathrm{KMnO}_{4}$, although the decolorization efficiency was as high as more than 85\% [17]. The limited mineralization may be ascribed to the recalcitrant structures (i.e., benzene ring, $-\mathrm{C}_{2} \mathrm{H}_{5}$, organic acids) within $\mathrm{X}-\mathrm{GRL}$, and $\mathrm{KMnO}_{4}$ at low $\mathrm{pH}$ level of 0.5 could hardly degrade these groups.

Basically, $\delta \mathrm{MnO}_{2}$ contributed to more rapid and more significant removal of DOC, ascribing to its good adsorptive activity to X-GRL. DOC removal significantly increased to $56.7 \%$ at $3.75 \mathrm{~min}$, and then attained to the maximum value of $65.0 \%$ at $13.5 \mathrm{~min}$ $(\mathrm{pH} 2.0)$. The longer reaction time decreased DOC removal to a certain extent, which decreased to $51.7 \%$ at $110 \mathrm{~min}$. Our former study demonstrated the promisingly adsorptive activities towards $\mathrm{X}$-GRL for $\equiv \mathrm{MnOH}$, and proposed the different interfacial interactions involved in the adsorption of X-GRL onto $\delta \mathrm{MnO}_{2}$ [20]. The oxidization of X-GRL and the formation of intermediates resulted in the detachment of X-GRL from $\equiv \mathrm{MnOH}$ surfaces, as being indicated from the decrease of DOC removal with higher reaction time. 


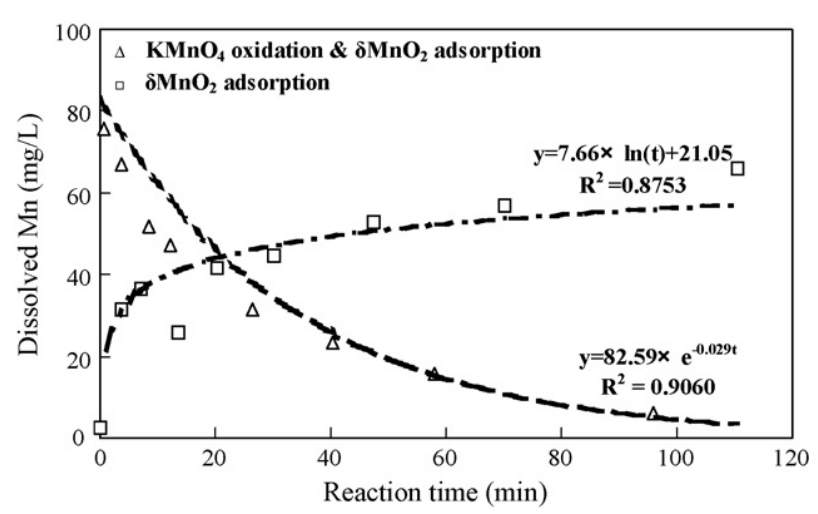

Fig. 3. Variations of filterable $\mathrm{Mn}$ concentrations for $\delta \mathrm{MnO}_{2}$ adsorption $(275 \mathrm{mg} / \mathrm{L}$ as $\left.\mathrm{MnO}_{2}\right)$, and $\mathrm{KMnO}_{4}$ oxidation and $8 \mathrm{MnO}_{2}$ adsorption $\left(500 \mathrm{mg} / \mathrm{L}\right.$ as $\left.\mathrm{KMnO}_{4}\right)$.

As for $\mathrm{KMnO}_{4}$ oxidation and $\delta \mathrm{MnO}_{2}$ adsorption, the maximum DOC removal of $39.4 \%$ was achieved at $1.2 \mathrm{~min}$ at $\mathrm{pH} 2.0$. After that, DOC removal decreased to $28.6 \%$ at $12.2 \mathrm{~min}$ and then showed no obvious variation with longer reaction time. At $\mathrm{pH} 7.2$, similar trends were observed except that the maximum DOC removal was slightly lower to be $32.9 \%$. The reactions between $\mathrm{KMnO}_{4}$ and X-GRL were rapid, which led to the degradation of X-GRL and the formation of $\delta \mathrm{MnO}_{2}$. The DOC removal was ascribed to the combined effects of $\mathrm{KMnO}_{4}$ oxidation and $\delta \mathrm{MnO}_{2}$ adsorption. However, the intermediates from X-GRL oxidation were more difficult to adsorb onto $\mathrm{SMnO}_{2}$ surfaces than X-GRL molecular. In the photodegradation of X-GRL on $\mathrm{TiO}_{2} / \mathrm{SiO}_{2}$ surfaces, $\mathrm{Hu}$ et al. also reported the formation of intermediates, and desorption of final products from catalyst [21]. The DOC removal of the $\mathrm{KMnO}_{4}$ oxidation and $\delta \mathrm{MnO}_{2}$ adsorption process was observed to be lower than that of $\delta \mathrm{MnO}_{2}$ adsorption. These results were in accordance with the decrease of DOC removal after the formation of intermediates in $\delta \mathrm{MnO}_{2}$ adsorption process.

\subsubsection{Variation of aqueous $\mathrm{Mn}^{2+}$ concentrations}

The $\mathrm{Mn}^{2+}$ in solution was an indicator to provide valuable information on the interactions between $\mathrm{X}-\mathrm{GRL}$ and $\mathrm{KMnO}_{4}$ and/or $\delta \mathrm{MnO}_{2}$. Fig. 3 compares the variation of dissolved Mn concentrations between the processes of $\delta \mathrm{MnO}_{2}$ adsorption and $\mathrm{KMnO}_{4}$ oxidation and $\delta \mathrm{MnO}_{2}$ adsorption. It should be noted that after the interactions between $\mathrm{KMnO}_{4}$ and X-GRL at $\mathrm{pH} 0.5$, the solution was observed to be transparent and absent of any particles. It was indicated that the dissolved Mn concentrations were constant for the process of $\mathrm{KMnO}_{4}$ oxidation at $\mathrm{pH} 0.5$, owing to the complete transformation of $\mathrm{Mn}(\mathrm{VII})$ to soluble $\mathrm{Mn}(\mathrm{II})$.

As for the $\delta \mathrm{MnO}_{2}$ adsorption process, the concentrations of dissolved $\mathrm{Mn}$, i.e., $\mathrm{Mn}^{2+}$, increased steadily with longer reaction time and the maximal value of $66.2 \mathrm{mg} / \mathrm{L}$ was achieved after $110 \mathrm{~min}$. The adsorption of X-GRL onto $\delta \mathrm{MnO}_{2}$ surfaces led to the reductive dissolution of $\mathrm{Mn}(\mathrm{IV})$ oxides to soluble $\mathrm{Mn}^{2+}$. The trends of $\mathrm{Mn}^{2+}$ concentrations variation may be fitted by logarithmic equation as follows:

$C_{\left[\mathrm{Mn}^{2+}\right] t}=7.66 \times \ln (t)+21.05 \quad\left(R^{2}=0.8753\right)$
However, the increasing rate of $\mathrm{Mn}^{2+}$ concentrations was observed to decrease with prolonged time, and was quantitatively demonstrated by the derivative formula of Eq. (4) as follows:

$\frac{d\left(C_{\left[\mathrm{Mn}^{2+}\right] t}\right)}{d t}=\left(\frac{7.66}{t}\right) d t$

The increase of $\mathrm{Mn}^{2+}$ concentrations demonstrated the oxidative activities of $\delta \mathrm{MnO}_{2}$ towards X-GRL, which led to the shift of absorption peaks in wavelength from 450 to $650 \mathrm{~nm}$ in Fig. 1c. Several studies have investigated the electron transfer between organics and $\delta \mathrm{MnO}_{2}$, reporting the reductive dissolution of $\mathrm{Mn}$ (IV) oxides and subsequent increase of $\mathrm{Mn}^{2+}$ concentrations [22,23].

As for the process of $\mathrm{KMnO}_{4}$ oxidation and $\delta \mathrm{MnO}_{2}$ adsorption at $\mathrm{pH} 2.0$, the dissolved $\mathrm{Mn}$, i.e., $\mathrm{Mn}(\mathrm{VII})$, decreased steadily with longer reaction time, and reached to the minimum value of $5.9 \mathrm{mg} / \mathrm{L}$ after $96 \mathrm{~min}$. Additionally, it was also observed that the decreasing rate of $\mathrm{Mn}(\mathrm{VII})$ concentrations reduced with longer time, and the trends of $\mathrm{Mn}(\mathrm{VII})$ variation were fitted by exponential equation as follows:

$C_{[\mathrm{Mn}(\mathrm{VII})] t}=82.59 \times e^{-0.029 t} \quad\left(R^{2}=0.9060\right)$

The derivative formula of Eq. (6) as follows indicated the tendency observed in Fig. 3:

$\frac{d\left(C_{[\mathrm{Mn}(\mathrm{VII})] t}\right)}{d t}=-2.40 \times e^{-0.029 t} d t$

The function groups with different reductive activities within $\mathrm{X}$ GRL dominated the variation of dissolved Mn in solution. The strong reductive function groups within X-GRL (i.e., azo group) exhibited high reactivity towards oxidative species of both $\mathrm{KMnO}_{4}$ and $\delta \mathrm{MnO}_{2}$, which contributed to the significant variation of dissolved Mn initially. After that, the recalcitrant groups within X-GRL and its intermediates were difficult to degrade and inhibited the variation of dissolved Mn.

It was interestingly observed that the dissolved Mn concentrations of the $\mathrm{KMnO}_{4}$ oxidation and $\mathrm{MnO}_{2}$ adsorption process were much lower than that of $\delta \mathrm{MnO}_{2}$ adsorption process, indicating that most $\mathrm{Mn}(\mathrm{VII})$ had transformed to solid phase of $\delta \mathrm{MnO}_{2}$. However, the newly formed $\delta \mathrm{MnO}_{2}$ from $\mathrm{Mn}$ (VII) reduction would not further transfer to $\mathrm{Mn}^{2+}$, even in the presence of organic intermediates which were resulted from the oxidation of X-GRL molecular. This was ascribed to the less activities of $\delta \mathrm{MnO}_{2}$ to the intermediates than to the X-GRL.

\subsubsection{Comparison of biodegradability variation among these processes}

As for the dye wastewater that is recalcitrant to biological treatment, the increase of biodegradability, through physic-chemical processes, is valuable to enable it to be treated through subsequent biological processes. The different mechanisms involved in the treatment of X-GRL by $\mathrm{KMnO}_{4}$ oxidation, $\delta \mathrm{MnO}_{2}$ adsorption, and $\mathrm{KMnO}_{4}$ oxidation and $\delta \mathrm{MnO}_{2}$ adsorption exhibited different effects on the biodegradability (Table 2).

$\mathrm{KMnO}_{4}$ oxidation at $\mathrm{pH} 0.5$ contributed to the highest $\mathrm{BOD}_{5}$ concentration of $42.47 \mathrm{mg} / \mathrm{L}$, which was followed by $\mathrm{KMnO}_{4}$ oxidation and $\delta \mathrm{MnO}_{2}$ adsorption at $\mathrm{pH} 0.8$ and $\mathrm{pH}$ 2.0. The $\delta \mathrm{MnO}_{2}$ adsorption at $\mathrm{pH} 2.0$ led to the lowest $\mathrm{BOD}_{5}$ concentration of $5.20 \mathrm{mg} / \mathrm{L}$, indicating the minimum increase of biodegradability. The variation of

Table 2

Comparison of biodegradability variation among $\mathrm{KMnO}_{4}$ oxidation, $\delta \mathrm{MnO}_{2}$ adsorption, and $\mathrm{KMnO}_{4}$ oxidation and $\delta M n \mathrm{M}_{2}$ adsorption $\left([\mathrm{X}-\mathrm{GRL}]_{0}=200 \mathrm{mg} / \mathrm{L}\right)$.

\begin{tabular}{|c|c|c|c|c|c|}
\hline Process & Dosage & $\mathrm{pH}$ & $\mathrm{BOD}_{5}(\mathrm{mg} / \mathrm{L})$ & $\mathrm{DOC}(\mathrm{mg} / \mathrm{L})$ & $\mathrm{BOD}_{5} / \mathrm{DOC}$ \\
\hline $\mathrm{KMnO}_{4}$ oxidation & $500 \mathrm{mg} / \mathrm{L}$ as $\mathrm{KMnO}_{4}$ & 0.5 & 42.47 & 25.42 & 1.67 \\
\hline$\delta \mathrm{MnO}_{2}$ adsorption & $275 \mathrm{mg} / \mathrm{L}$ as $\mathrm{MnO}_{2}$ & 2.0 & 5.20 & 16.90 & 0.31 \\
\hline $\mathrm{KMnO}_{4}$ oxidation and $\mathrm{MnO}_{2}$ adsorption & $500 \mathrm{mg} / \mathrm{L}$ as $\mathrm{KMnO}_{4}$ & 2.0 & 14.64 & 23.28 & 0.63 \\
\hline $\mathrm{KMnO}_{4}$ oxidation and $\delta \mathrm{MnO}_{2}$ adsorption & $500 \mathrm{mg} / \mathrm{L}$ as $\mathrm{KMnO}_{4}$ & 0.8 & 24.40 & 24.92 & 0.98 \\
\hline
\end{tabular}



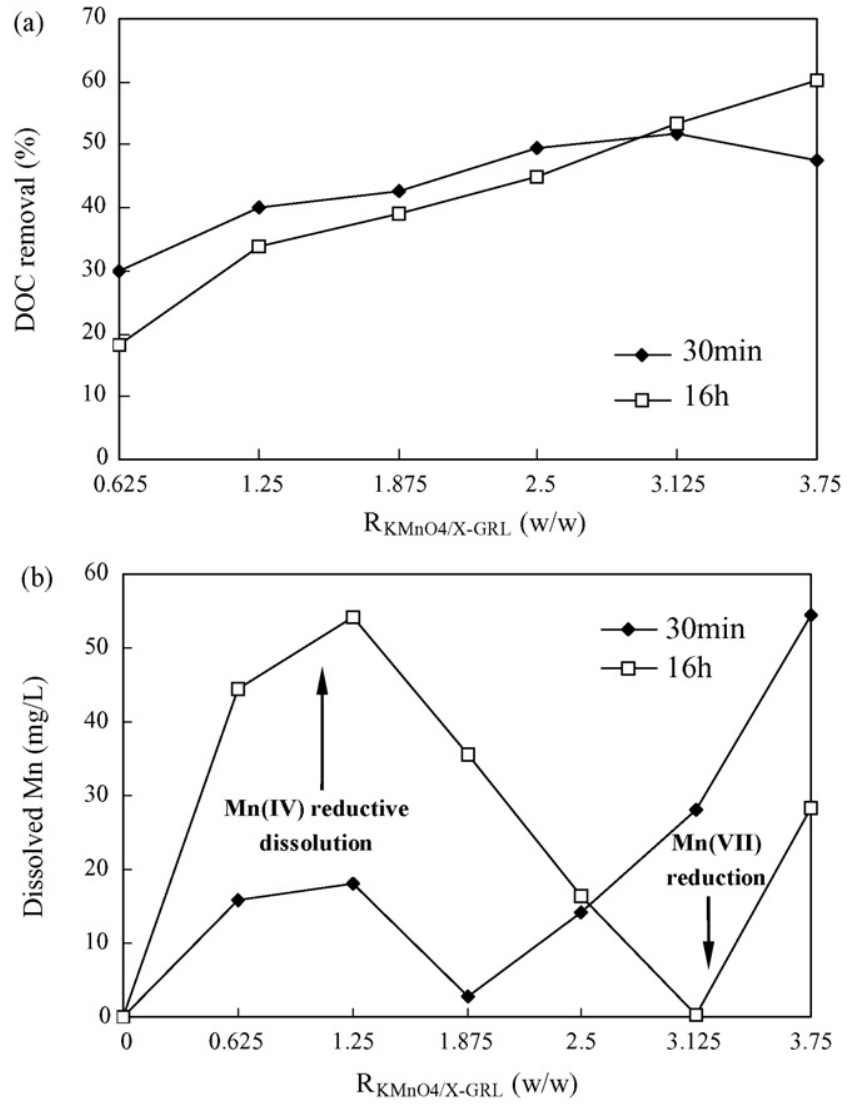

Fig. 4. Variation of DOC removal and filterable Mn concentrations at different ratios of permanganate to X-GRL.

ratio of $\mathrm{BOD}_{5}$ to $\mathrm{DOC}\left(\mathrm{BOD}_{5} / \mathrm{DOC}\right)$ also followed same sequence to $\mathrm{BOD}_{5}$ as follows: $\mathrm{KMnO}_{4}$ oxidation $>\mathrm{KMnO}_{4}$ oxidation and $\delta \mathrm{MnO}_{2}$ adsorption $>\delta \mathrm{MnO}_{2}$ adsorption, with the highest value of 1.67. Xu et al. reported that the treatment of a real textile wastewater by $\mathrm{KMnO}_{4}$ at $\mathrm{pH} 0.5$ could promisingly improved the biodegradability, which increased the ratio of $\mathrm{BOD}_{5} / \mathrm{COD}$ from 0.0081 to 0.32 [17], and that $\mathrm{KMnO}_{4}$ oxidation may be feasible as pretreatment before biological process.

In comparison, $\delta \mathrm{MnO}_{2}$ adsorption led to the lowest increase of biodegradability, although the residual DOC was the lowest among these processes. $\mathrm{KMnO}_{4}$ oxidation at $\mathrm{pH} 0.5$ contributed to the most significant increase of biodegradability; however, the large amount of acid for $\mathrm{pH}$ adjustment increased the cost for treatment, and the low $\mathrm{pH}$ levels inhibited the growth of bacteria for further biological processes. Consequently, the treatment by $\mathrm{KMnO}_{4}$ oxidation and $\delta \mathrm{MnO}_{2}$ adsorption at $\mathrm{pH} 2.0$, prior to the biological processes, was the optimum strategy in practice for the treatment of dyes (e.g., X-GRL) wastewaters.

\subsection{Treatment of X-GRL by $\mathrm{KMnO}_{4}$ oxidation and $\delta \mathrm{MnO}_{2}$ adsorption}

\subsubsection{Effects of $\mathrm{KMnO}_{4}$ dosages on the treatment of X-GRL}

The dosages of $\mathrm{KMnO}_{4}$ impacted the treatment of X-GRL. The higher dosages of $\mathrm{KMnO}_{4}$ improved X-GRL oxidation and provided more $\delta \mathrm{MnO}_{2}$ for adsorption. Fig. 4 presents the variation of DOC removal and dissolved $\mathrm{Mn}$ concentrations at different $\mathrm{KMnO}_{4}$ dosages. With the ratios of $\mathrm{KMnO}_{4}$ to X-GRL $\left(R_{\mathrm{KMnO}_{4} / \mathrm{X}-\mathrm{GRL}}\right)$ increasing from 0.625 to $3.125(\mathrm{w} / \mathrm{w})$, the DOC removal at $30 \mathrm{~min}$ accordingly increased from $29.9 \%$ to $53.4 \%$ (Fig. $4 a$ ). The higher $R_{\mathrm{KMnO}_{4} / \mathrm{X} \text {-GRL }}$ value of 3.75 slightly decreased DOC removal to $47.5 \%$. The prolonged reaction time of $16 \mathrm{~h}$ improved DOC removal to
$60.3 \%$ at $R_{\mathrm{KMnO}_{4} / \mathrm{X} \text {-GRL }}$ of 3.75 , but exhibited side effects on DOC

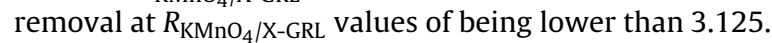

The variation of dissolved Mn concentrations provides valuable information on the mechanisms involved in these reactions. Fig. $4 \mathrm{~b}$ indicates the variation of dissolved Mn concentrations at differ-

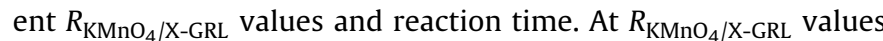
of lower than 2.5, the dissolved Mn concentrations increased to higher levels with longer reaction time, owing to the reductive dissolution effect of $\mathrm{Mn}(\mathrm{IV})$ oxides. Comparatively, the dissolved Mn concentrations at $R_{\mathrm{KMnO}_{4} / \mathrm{X}-\mathrm{GRL}}>2.5$ accordingly decreased to lower values, ascribing to the reduction effect of soluble $\mathrm{Mn}(\mathrm{VII})$ to $\mathrm{Mn}(\mathrm{IV})$ oxides.

At low $\mathrm{KMnO}_{4}$ dosages, the oxidative capabilities were insufficient to oxidize the reductive functional groups within X-GRL molecular, and further resulted in the reduction of $\mathrm{Mn}(\mathrm{IV})$ oxides to aqueous $\mathrm{Mn}(\mathrm{II})$ through interfacial reductive reactions. The adsorbed organics (i.e., X-GRL, intermediates) detached from $\mathrm{Mn}(\mathrm{IV})$ oxides, together with the dissolved $\mathrm{Mn}(\mathrm{II})$, and resulted in the decrease of DOC removal. At $R_{\mathrm{KMnO}_{4} / \mathrm{X} \text {-GRL }}>2.5$, the excess of $\mathrm{KMnO}_{4}$ further reacted with the intermediates with longer time, and resulted in the formation of more $\mathrm{Mn}(\mathrm{IV})$ oxides for the adsorption of intermediates onto $\delta \mathrm{MnO}_{2}$ surfaces. The optimum

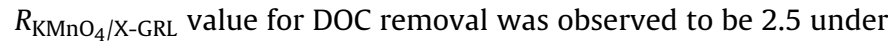
these conditions.

\subsubsection{Effects of $p H$ on the treatment of X-GRL}

$\mathrm{pH}$ was an important factor affecting the treatment of X-GRL wastewater by $\mathrm{KMnO}_{4}$ oxidation. The low $\mathrm{pH}$ was beneficial to the oxidation of X-GRL. However, the excessive degradation of X-GRL inhibited the adsorption of intermediate products onto $\delta \mathrm{MnO}_{2}$, as being indicated above. Additionally, the adjustment of $\mathrm{pH}$ to much too low levels increased the costs.

Fig. 5 presents the variation of dissolved Mn concentrations and DOC removal with $\mathrm{pH}$ increasing from 1.0 to $9.6\left(R_{\mathrm{KMnO}_{4} / \mathrm{X}-\mathrm{GRL}}=\right.$ 2.5). The concentrations of dissolved $\mathrm{Mn}$ at $\mathrm{pH}<2$ were much lower than those in $\mathrm{pH}$ ranges from 2.8 to 9.6 at $30 \mathrm{~min}$. The low dissolved Mn concentrations indicated the complete reaction between $\mathrm{KMnO}_{4}$ and X-GRL, which was favored at low $\mathrm{pH}$ as being indicated from Eqs. (1)-(3). $\mathrm{KMnO}_{4}$ was more reactive and showed higher oxidizing capabilities under strong acid conditions than that at elevated $\mathrm{pH}$ conditions.

Additionally, the species transformation of elemental Mn with longer time was indicative to the extent of reactions between $\mathrm{KMnO}_{4}$ and X-GRL. It is observed in Fig. 5 that the concentrations of dissolved $\mathrm{Mn}$ at $\mathrm{pH}>2.8$ decreased with reaction time increasing from $30 \mathrm{~min}$ to $18 \mathrm{~h}$, and this was ascribed to the reduction of excess soluble $\mathrm{Mn}(\mathrm{VII})$ to $\mathrm{Mn}(\mathrm{IV})$ oxides particles. At $\mathrm{pH}<2$, how-

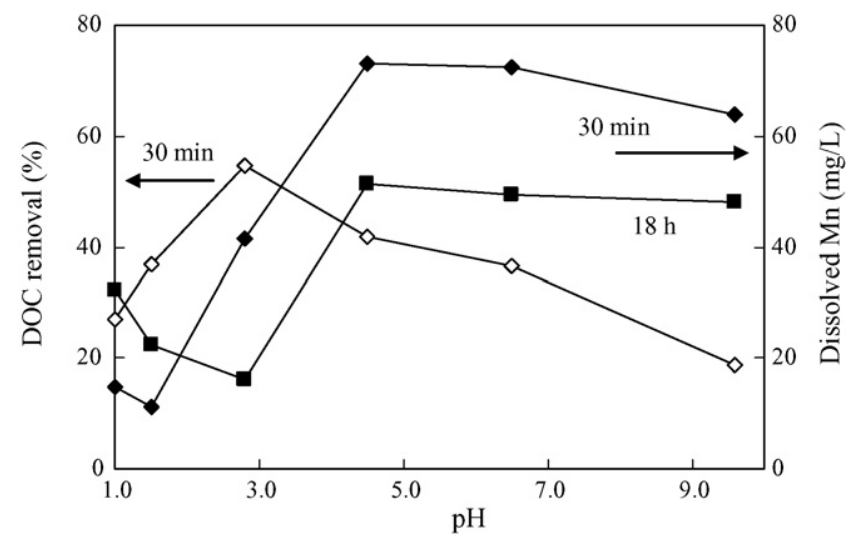

Fig. 5. Variation of DOC removal and filterable Mn concentrations at different $\mathrm{pH}$ conditions. 
ever, the concentrations of dissolved Mn accordingly increased due to the reductive dissolution of $\mathrm{Mn}$ (IV) oxides to soluble $\mathrm{Mn}(\mathrm{II})$.

With $\mathrm{pH}$ increasing from 1.0 to 9.6 , DOC removal at reaction time of 30 min firstly increased from $26.9 \%$ at pH 1.0 to the maximum value of $54.6 \%$ at $\mathrm{pH} 2.8$, and then steadily decreased with elevated $\mathrm{pH}$ values. The minimum removal of DOC of $18.9 \%$ was observed at $\mathrm{pH} 9.6$. The removal of $\mathrm{DOC}$ by $\mathrm{KMnO}_{4}$ adsorption and $\delta \mathrm{MnO}_{2}$ adsorption was dominated by the extent of the degradation of X-GRL, and the adsorptive behaviors of the intermediates onto $\delta \mathrm{MnO}_{2}$. The dissolved Mn concentration at $\mathrm{pH} 1.0$ was lower than that at $\mathrm{pH} 2.8$, and indicating that $\mathrm{KMnO}_{4}$ at $\mathrm{pH} 1.0$ provided more $\mathrm{Mn}$ (IV) oxides than that at $\mathrm{pH} 2.8$. However, the DOC removal at $\mathrm{pH}$ 1.0 was lower than that at $\mathrm{pH} 2.8$, demonstrating that the excess degradation of X-GRL molecular was inhibitive to the removal of DOC. This result was in accordance with that in Fig. 2.

Additionally, Fig. 5 indicates that the DOC removal decreased with elevated $\mathrm{pH}$ in $\mathrm{pH}$ ranges from 2.8 to 9.6 , although the concentrations of dissolved Mn were similar from $\mathrm{pH} 4.5$ to $\mathrm{pH} 9.6$. The higher $\mathrm{pH}$ decreased the surface charge of $\delta \mathrm{MnO}_{2}$, and benefited the adsorption of positively charged X-GRL molecular onto $\delta \mathrm{MnO}_{2}$ surfaces [20]. In this study, X-GRL was firstly oxidized by $\mathrm{KMnO}_{4}$ to negative species such as organic acids. The adsorption of these intermediates onto $\mathrm{\delta MnO}_{2}$ at elevated $\mathrm{pH}$ was inhibited by the increased repulsive forces between intermediates and negative surfaces of $\delta \mathrm{MnO}_{2}$.

The optimum $\mathrm{pH}$ for the treatment of X-GRL wastewater was observed to be near 3.0 under these conditions.

\section{Conclusions}

As for the treatment of dye wastewater with high color, high $\mathrm{COD}$, and low biodegradability, the addition of $\mathrm{KMnO}_{4}$ at $\mathrm{pH}$ value near to 3, is shown to be feasible as a pretreatment prior to the biological process, owing to the combined effects of $\mathrm{KMnO}_{4}$ oxidation and $\delta \mathrm{MnO}_{2}$ adsorption. Basically, $\mathrm{KMnO}_{4}$ oxidation mainly contributes to the decolorization and the increase of biodegradability, although it also leads to the $\mathrm{DOC}$ removal. $\delta \mathrm{MnO}_{2}$ acts as adsorbent for the removal of X-GRL and its oxidative intermediates. In comparison, $\mathrm{KMnO}_{4}$ oxidation alone at $\mathrm{pH} 0.5$ requires a great deal of acid for $\mathrm{pH}$ adjustment, and the low $\mathrm{pH}$ level is inhibitive to subsequent biological units. $\delta \mathrm{MnO}_{2}$ alone exhibits promising adsorptive activity to X-GRL, but showed limited capability of increasing its biodegradability. The moderate oxidation of X-GRL molecular by $\mathrm{KMnO}_{4}$ and the formation of sufficient $\delta \mathrm{MnO}_{2}$ for the adsorption of its intermediates can be achieved by adjusting the parameters (i.e., $\mathrm{KMnO}_{4}$ dosage, $\mathrm{pH}$ ).

\section{Acknowledgments}

This work was supported by the Funds for the Creative Research Groups of China (50621804) and the National Natural Sciences
Foundation of China (50778172). Appreciation is extended to the foundation for financial assistance.

\section{References}

[1] T. Hedberg, T.A. Wahlberg, Upgrading of waterworks with a new biooxidation process for removal of manganese and iron, Water Sci. Technol. 37 (1998) 121-126.

[2] N. Li, M.H. Fan, V.L. Johannes, S. Basudeb, H.Q. Yang, C.P. Huang, Oxidation of As(III) by potassium permanganate, J. Environ. Sci. 19 (2007) 783-786.

[3] A. Bruchet, J.P. Duguet, I.H. Suffe, Role of oxidants and disinfectants on the removal, masking and generation of tastes and odours, Rev. Environ. Sci. Biotechnol. 3 (2004) 33-41.

[4] B. Moyers, J.S. Wu, Removal of organic precursors by permanganate oxidation and alum coagulation, Water Res. 19 (1985) 309-314.

[5] J.J. Chen, H.H. Yeh, The mechanisms of potassium permanganate on algae removal, Water Res. 39 (2005) 4420-4428.

[6] K.C. Huang, G.E. Hoag, P. Chheda, B.A. Wody, G.M. Dobbs, Kinetics and mechanism of oxidation of tetrachloroethylene with permanganate, Chemosphere 46 (2002) 815-825.

[7] H.S. Posselt, F.J. Anderson, J.W.J. Walter, Cation sorption on colloidal hydrous manganese dioxide, Enviorn. Sci. Technol. 2 (1968) 1087-1093.

[8] R.P. Liu, Y.L. Yang, G.B. Li, W.J. He, H.D. Han, Adsorptive behaviors of humic acid onto freshly prepared hydrous manganese dioxides, Front. Environ. Sci. Eng. China 1 (2007) 1-6.

[9] W.Yao, F.J. Millero, Adsorption of phosphate on manganese dioxide in seawater, Environ. Sci. Technol. 30 (1996) 536-541.

[10] R.P. Liu, B.L. Yuan, X. Li, S.J. Xia, Y.L. Yang, G.B. Li, The oxidative and adsorptive effectiveness of hydrous manganese dioxide for arsenite removal from aqueous solution, High Technol. Lett. 12 (2006) 30-34.

[11] C. O'Neill, F.R. Hawkes, D.L. Hawkes, N.D. Lourenco, H.M. Pinheiro, W. Dele'e, Colour in textile effluents-sources, measurement, discharge consents and simulation: a review, J. Chem. Technol. Biotechnol. 74 (1999) 1009-1018.

[12] P.C. Vandevivere, R. Bianchi, W. Verstraete, Treatment and reuse of wastewater from the textile wet-processing industry: review of emerging technologies, J. Chem. Technol. Biotechnol. 72 (1998) 289-302.

[13] M.S. Lucas, J.A. Peres, Decolorization of the azo dye Reactive Black 5 by Fenton and photo-Fenton oxidation, Dyes Pigments 71 (2006) 236-244.

[14] H.Y. Shu, M.C. Chang, Development of a rate expression for predicting decolorization of C.I. Acid Black 1 in a UV- $\mathrm{H}_{2} \mathrm{O}_{2}$ process, Dyes Pigments 70 (2006) 31-37.

[15] Y.Z. Wang, A. Yedeler, A. Kettrup, Comparison of degradation reactions of Acid Yellow 61 in both oxidation processes of $\mathrm{H}_{2} \mathrm{O}_{2} / \mathrm{UV}$ and $\mathrm{O}_{3}$, J. Environ. Sci. 13 (2001) 304-307.

[16] F.B. Li, G.B. Gu, G.F. Huang, Y.L. Gu, $\mathrm{TiO}_{2}$-assisted photo-catalysis degradation process of dye chemicals, J. Environ. Sci. 13 (2001) 62-68.

[17] X.P. Xu, H.B. Li, W.H. Wang, J.D. Gu, Decolorization of dyes and textile wastewater by potassium permanganate, Chemosphere 59 (2005) 893-898.

[18] A. Aleboyeh, M.E. Olya, H. Aleboyeh, Oxidative treatment of azo dyes in aqueous solution by potassium permanganate, J. Hazard. Mater. 162 (2009) 1530-1535.

[19] J.W. Murray, The surface chemistry of hydrous manganese dioxide, J. Colloid Interface Sci. 46 (1974) 357-371.

[20] R.P. Liu, H.J. Wang, X. Zhao, S.H. Xiao, J.H. Qu, Microwave electrodeless lamp assisted catalytic degradation of X-GRL with manganese dioxides: adsorption and manganese(IV) reductive dissolution effects, Catal. Today 139 (2008) 119-124.

[21] C. Hu, Y. Tang, J.C. Yu, P.K. Wong, Photocatalytic degradation of cationic blue X-GRL adsorbed on $\mathrm{TiO}_{2} / \mathrm{SiO}_{2}$ photocatalyst, Appl. Catal. B: Environ. 40 (2003) $131-140$.

[22] A. Stone, J. Morgan, Reduction and dissolution of manganese(III) and manganese(IV) oxides by organics: 2 . Survey of the reactivity of organics, Environ. Sci. Technol. 18 (1984) 617-624.

[23] R. Petrie, P. Grossl, R. Sims, Oxidation of pentachlorophenol in manganese oxide suspensions under controlled $\mathrm{E}_{\mathrm{h}}$ and $\mathrm{pH}$ environments, Environ. Sci. Technol. 36 (2002) 3744-3748. 